\title{
UPdate of Clostridium difficile infeCtion dUe to PCR RIBOTYPE 027 IN EUROPE, 2008
}

E J Kuijper (ejkuijper@gmail.com)1 ${ }^{1}$, F Barbut ${ }^{2}$, J S Brazier ${ }^{3}$, N Kleinkauf ${ }^{4}$, T Eckmanns ${ }^{4}$, M L Lambert ${ }^{5}$, D Drudy ${ }^{6}$, F Fitzpatrick7, C Wiuff ${ }^{8}$, D J Brown ${ }^{9}$, J E Coia ${ }^{9}$, H Pituch ${ }^{10}$, P Reichert ${ }^{11}$, J Even ${ }^{11}$, J Mossong ${ }^{11}$, A F Widmer ${ }^{12}$, K E Olsen ${ }^{13}$, F Allerberger ${ }^{14}$, D W Notermans ${ }^{15}$, M Delmée ${ }^{16}$, B Coignard ${ }^{17}$, M Wilcox ${ }^{18}$, B Patel ${ }^{19}$, R Frei ${ }^{20}$, E Nagy ${ }^{21}$, E Bouza B $^{22}$ M Marin ${ }^{10}$, T Åkerlund ${ }^{23}$, A Virolainen- Julkunen ${ }^{24}$, 0 Lyytikäinen ${ }^{24}$, S Kotila ${ }^{24}$, A Ingebretsen ${ }^{25}$, B Smyth ${ }^{26}$, P Rooney ${ }^{27}$, I R Poxton ${ }^{28}$, D. L. Monnet ${ }^{29}$

1. National Reference Laboratory for Clostridium difficile. Leiden University Medical Center, Leiden, The Netherlands

2. National Reference Center for Clostridium difficile, Saint-Antoine Hospital, Paris, France

3. Anaerobe Reference Laboratory, National Public Health Service for Wales Cardiff, University Hospital of Wales, Cardiff, United Kingdom

4. Department for Infectious Disease Epidemiology, Robert Koch Institute, Berlin, Germany

5. Epidemiology Unit, Scientific Institute of Public Health, Brussels, Belgium

6. Centre for Food Safety, Food Science and Veterinary Medicine, University College Dublin, Dublin, Ireland

7. Health Protection Surveillance Centre and Beaumont Hospital, Dublin, Ireland

8. Health Protection Scotland, Section for Healthcare Associated Infection and Infection Control, Glasgow, United Kingdom

9. Scottish Clostridium difficile Reference Service, Stobhill Hospital, Glasgow, United Kingdom

10. Department of Medical Microbiology, Medical University of Warsaw, Warsaw, Poland

11. Division of Microbiology, National Public Health Laboratory, Luxembourg

12. Division of Infectious diseases and Hospital Epidemiology, University Hospital, Basel, Switzerland

13. National Reference Laboratory for Enteropathogens, Statens Serum Institut, Copenhagen, Denmark

14. Österreichische Agentur für Gesundheit und Ernährungssicherheit (Austrian Agency for Health and Food Safety; AGES), Vienna, Austria

15. Centrum Infectieziektebestrijding (Centre for Infectious Disease Control; CIb), Rijksinstituut voor Volksgezondheid en Milieu (National Institute for Public Health and the Environment; RIVM), Bilthoven, The Netherlands

16. Microbiology Department, Saint-Luc University Hospital, Brussels, Belgium

17. Departement of Infectious Diseases, Institut de Veille Sanitaire (National Public Health Institute; InVS), Saint-Maurice, France

18. Clostridium difficile Ribotyping Network for England (CDRNE), Health Protection Agency, Reference Leeds General Infirmary, Leeds, United Kingdom

19. 0 Health Protection Agency, London, United Kingdom

20. Microbiology Laboratory, University Hospital, Basel, Switzerland

21. Department of Clinical Microbiology, Faculty of Medicine, University of Szeged, Szeged, Hungary

22. Department of Medical Microbiology, University General Hospital Gregorio Maranon, Madrid, Spain

23. Smittskyddsinstitutet (Swedish Institute for Infectious Disease Control; SMI), Solna, Sweden

24. Kansanterveyslaitos (National Public Health Institute; KTL), Helsinki, Finland

25. Department of Infection Prevention, Rikshospitalet, Oslo, Norway

26. Health Protection Agency, Communicable Disease Surveillance Centre (Northern Ireland), Belfast, United Kingdom

27. Microbiology Laboratory Belfast City Hospital, Belfast, United Kingdom

28. Medical Microbiology, Centre for Infectious Diseases, University of Edinburgh College of Medicine and Veterinary Medicine, Edinburgh, United Kingdom

29. European Centre for Disease Prevention and Control, Stockholm, Sweden

Outbreaks of Clostridium difficile infections (CDI) with increased severity, high relapse rate and significant mortality have been related to the emergence of a new, hypervirulent $C$. difficile strain in North America and Europe. This emerging strain is referred to as PCR ribotype 027 (Type 027). Since 2005, individual countries have developed surveillance studies about the spread of type 027. C. difficile Type 027 has been reported in 16 European countries. It has been responsible for outbreaks in Belgium, Germany, Finland, France, Ireland, Luxembourg, The Netherlands, Switzerland and the United Kingdom (England, Wales, Northern Ireland and Scotland).
It has also been detected in Austria, Denmark, Sweden, Norway, Hungary, Poland and Spain. Three countries experienced imported patients with $\mathrm{CDI}$ due to Type 027 who acquired the infection abroad. The antimicrobial resistance pattern is changing, and outbreaks due to clindamycin-resistant ermB positive Type 027 strains have occurred in three European countries. Ongoing epidemiological surveillance of cases of CDI, with periodic characterisation of the strains involved, is required to detect clustering of cases in time and space and to monitor the emergence of new, highly virulent clones. 


\section{Introduction}

Since the emergence of a new virulent strain of Clostridium difficile characterised as toxinotype III, North American pulsedfield type 1 (NAP1), restriction-endonuclease analysis group type $\mathrm{BI}$ and PCR-ribotype 027 (Type 027), multiple outbreaks have been reported in North America and Europe [1-9]. The increased virulence of $C$. difficile Type 027 is thought to be associated with a 1 base pair deletion at position 117 of the tcdC gene which leads to an increased or prolonged production of toxins $A$ and $B$, and possibly the production of a binary toxin [1-3]. However, these virulence factors are not unique for Type 027 and are also present in other PCR ribotypes.

The first reports of outbreaks of $C$. difficile infections (CDI) due to Type 027 came from Canada, and the province of Quebec was the one affected first and most severely [4]. In the United States, cases of $C$. difficile Type 027 infection have been reported from at least 38 states (http://www.cdc.gov/ncidod/dhqp/id_Cdiff.html), and surveillance of community-acquired CDI has started [10]. By 2007, C. difficile Type 027 had been detected in 11 European countries [9]. The present report is an update on the situation in Europe in 2008.

\section{Surveillance efforts}

In 2005, the European Study Group for Clostridium difficile (ESGCD) performed a two-month surveillance study in 38 hospitals from 14 European countries [5]. Unfortunately, only hospitalacquired CDI were studied and no precise information on the severity and outcome was collected. The mean incidence of CDI was $2.45+/-1.8$ cases per 10,000 patient-days. The distribution of PCR ribotypes varied among hospitals and countries. Of 322 toxinogenic isolates, $20(6.2 \%)$ belonged to Type 027 and were reported from Ireland, Belgium and The Netherlands. Patients infected with Type 027 were more likely to have a more severe disease, and to have been treated by metronidazole or vancomycin compared to patients infected by another PCR ribotype.

The European Centre for Disease Prevention and Control (ECDC) recognised this emerging new disease and undertook several actions to inform all European Union (EU) Member States. ECDC also offered support for surveillance studies at national and European level. Another pan-European surveillance study is presently being organised, which will collect epidemiological and microbiological data for one month in a selected number of hospitals from all EU Member States in order to estimate the incidence of hospitalacquired as well as community-acquired CDI. The results of this study are expected to be available in 2009.

\section{Austria}

In Austria, C. difficile Type 027 was reported once in 2006 in a British tourist suffering from pseudomembranous colitis. In May 2008, two cases of CDI due to Type 027 were found in patients who had no travel history in the year before their hospitalisation [11]. Typing patterns of isolates submitted voluntarily since 2006 demonstrate the occurrence of non-027 clusters of CDI cases in Austrian hospitals. The largest cluster affected a tertiary teaching hospital in 2006, where $C$. difficile PCR ribotype 053 represented 10 of $21 \mathrm{CDI}$ cases. CDI is not a reportable disease in Austria. Hospital discharge data indicate a significant increase of CDI during the last years, from 777 cases (54 deaths) in 2003 to 997 cases (80 deaths) in 2004, 1,453 cases (88 deaths) in 2005 and 2,192 cases (150 deaths) in 2006.

\section{Belgium}

In Belgium, laboratory-based surveillance of CDI clusters performed by the national reference laboratory at the Universite Catholique de Louvain as well as prospective surveillance of CDI incidence in acute care hospitals monitored by the Institute for Public Health were initiated in January 2006. Surveillance of CDI has become a legal obligation since July 2007. In 2007, 896 C. difficile isolates were analysed at the reference laboratory.

With $17.6 \%$ (158 isolates) Type 027 was the most frequently found type. Other frequently found types were PCR ribotypes 078 and 031 , accounting for $6.3 \%$ and $5.6 \%$ of these isolates, respectively. Overall, the mean (median) incidence of CDI was 1.7 (1.6) cases per 1,000 admissions and 2.07 (1.86) cases per 10,000 hospital days. Sixty-eight percent of these cases occurred more than two days after hospital admission.

\section{Denmark}

In April 2006, Statens Serum Institut encouraged the Danish departments of clinical microbiology to report $C$. difficile cases on a continuous basis and to forward isolates for characterisation in cases of severe disease or in outbreak situations. In a retrospective survey covering a county in Region South Denmark, a cluster of eight patients with $C$. difficile Type 027 was detected. The isolates were recovered from 22 faecal samples that had been collected between November 2006 and March 2007. All eight cases were hospitalised in two hospitals in the region. Subsequently, active surveillance was initiated in the same region for the period JuneAugust 2007, which resulted in five additional Type 027 cases among 22 C. difficile isolates tested. Interestingly, all 13 isolates were resistant to newer fluoroquinolones and cephalosporins, but susceptible to erythromycin and clindamycin.

\section{Finland}

The first case of $C$. difficile Type 027-associated disease was detected in Finland in October 2007 [12]. Since then the National Public Health Institute (Kansanterveyslaitos; KTL) has intensified surveillance and control of CDI. A few additional cases caused by Type 027 were detected retrospectively, indicating that this strain had previously been circulating in Finland. The Finnish Hospital Infection Programme (SIRO) prepared a protocol for CDI surveillance to detect severe cases and epidemics caused by $C$. difficile. Molecular methods for rapid detection of $C$. difficile Type 027 were set up at two clinical, university-affiliated laboratories in Helsinki and Turku, and genotyping methods for molecular epidemiology of $C$. difficile were set up at KTL.

During the five-month-period from mid-October 2007 to midMarch 2008, isolates of $C$. difficile Type 027 were reported from four of the nine health care districts that had sent the isolates to KTL, and originated from over 20 different health care facilities - most of them providing primary or long term care - located in southern and south-western Finland. Of the 268 isolates, 131 (49\%) belonged to Type 027 . The remaining isolates were distributed among more than 30 different PCR ribotypes.

\section{France}

In France, the CDI surveillance is based on the mandatory notification of severe cases or outbreaks of CDI to local health departments, regional infection control coordinating centres and the National Institute for Public Health (Institut de Veille Sanitaire; 
InVS). Laboratories are encouraged to send the isolates from notified cases to a network of six French reference laboratories for C. difficile.

In April 2006, the first cluster of $C$. difficile Type 027 was reported in Northern France. From January 2006 to December 2007, 214 health care facilities reported at least one severe case or outbreak of CDI and a total of 1,247 cases. Sixty-four health care facilities (29 in 2006 and 35 in 2007, with no overlap between these 64) were affected by Type 027 . Most cases originated from healthcare facilities in the Nord Pas-de-Calais region, but in 2007, small clusters of $C$. difficile Type 027 were reported from three other French regions, Picardie, Rhône-Alpes and Lorraine. Among the 1,227 isolates (511 in 2006 and 716 in 2007) sent for typing, 337 (27.5\%) were identified as Type 027 (212 in 2006, i.e. $41.5 \%$ of the typed isolates, and 125 in 2007 , i.e. $17.4 \%$ of the typed isolates). The large majority of strains were resistant to erythromycin and moxifloxacin, but susceptible to clindamycin. However, one hospital in Picardie reported an outbreak associated with a clindamycin-resistant strain that tested positive for the ermB gene encoding the macrolide-lincosamide-streptogramin B (MLSB) phenotype.

Unfortunately, no data are available on the occurrence of other PCR ribotypes.

\section{Germany}

Since October 2007, it is mandatory to report severe cases of $\mathrm{CDI}$ to the local authorities. Patient-based notifications are done by the physician treating the patient. Severe CDI cases are defined as cases which necessitate readmission to a healthcare facility due to the relapse of CDI, admission to an intensive care unit for treatment of CDI or its complications, surgery (colectomy) for toxic megacolon, perforation or refractory colitis, or lead to death within 30 days after diagnosis of CDI, if CDI is either the primary or a contributive cause to death. This mandatory surveillance was implemented shortly after the first outbreak of $C$. difficile Type 027 was detected in the region of Trier, Rhineland-Palatine in September 2007. To date, five of 16 Federal States (Länder), all of which are located in the south-west of Germany, have reported cases of CDI due to Type $027[13,14]$

\section{Hungary (not included in the table)}

A recently completed surveillance study in three different parts of Hungary revealed one isolate of Type 027 among $150 \mathrm{C}$. difficile isolates collected. The patient had systemic lupus erythematosus and developed severe CDI after antibiotic treatment for pneumonia in a hospital in Budapest.

\section{Ireland}

After the first report of C. difficile Type 027 in Ireland in 2007, this type was identified in six additional healthcare settings $[15,16]$. To date, more than 100 C. difficile Type 027 isolates from Ireland have been characterised by toxinotyping and 16-23S PCR ribotyping [15]. Isolates from two healthcare settings were susceptible to clindamycin $(n=11: M I C 90=4 \mathrm{mg} / \mathrm{l})$. However, clindamycin-resistant Type 027 isolates $(n=96$, MIC90>256 mg/l) were identified in the five other healthcare institutions. All clindamycin-resistant Type 27 isolates tested positive for the ermB gene. Multiple locus variable number tandem repeat (MLVA) typing could clearly differentiate between clindamycin-resistant and -susceptible isolates from the same geographical region and sub-grouped them into two distinct clusters, with all isolates from the clindamycin-resistant cluster being were closely related [16].

$\mathrm{CDI}$ has become a notifiable disease in the Republic of Ireland since May 2008 under 'acute infectious gastroenteritis' using the case definition by ESGCD and ECDC. Only new cases will be reported, and this will enable data to be collected on the national level, but not on hospital-level. There are moves to make CDI notifiable in its own right to enable the collection of enhanced surveillance data (e.g. on origin and onset of CDI). National guidelines on surveillance, diagnosis and management of $C$. difficile have been published in May 2008 [17].

\section{Luxembourg}

During the period between October 2006 (start of CDI surveillance in Luxembourg) and February 2008, 96 (26\%) of 368 submitted C. difficile strains were PCR ribotyped as Type 027 . Type 027 was the type found most frequently, followed by types 001 and 106, but confirmation for the latter two is pending. The isolates came from all 10 hospitals in Luxembourg. The situation is ongoing and the total number of $C$. difficile isolates is now exceeding the number of salmonella and campylobacter isolates.

The median age significantly differed between patients with Type 027 (74 years) and patients with other ribotypes (59 years) $(p=0.001)$. The mortality rate of $C D I$ due to Type 027 within one month and within three months of isolate referral was $14.8 \%$ and $21.0 \%$, respectively. In a logistic regression model, one-month mortality of CDI was significantly associated with age over 70 years $(p<0.0001)$, but not with gender $(p=0.66)$ or PCR ribotype $(p=0.14)$

\section{Netherlands}

Since October 2005, the Centre for Infectious Disease Control (Clb) at the National Institute for Public Health and the Environment (Rijks Instituut voor Volksgezondheid en Milieu; RIVM) and the reference laboratory for $C$. difficile at Leiden University Medical Center have encouraged microbiologists to send $C$. difficile isolates from patients with a severe course of CDI, or when an increased incidence of CDI was noticed. During the surveillance period from 2005 to 2007, Type 027 was reported from an increasing number of healthcare facilities in an endemic form or in outbreaks. At the end of 2007, 35 healthcare facilities have been affected, compared to 22 healthcare facilities until the end of 2006 [8]. During the surveillance period of 2006/2007, five outbreaks with Type 027 occurred, compared to 11 outbreaks in 2005/2006. One hospital was affected by an outbreak caused by both Type 027 and Type 017.

Comparison of clinical data of patients with CDI due to Type $027(n=128)$ and other types $(n=443)$ showed that CDI due to Type 027 was associated with older age, use of cephalosporins (mainly second generation) and fluoroquinolones (mainly ciprofloxacin). Patients with Type $027 \mathrm{CDI}$ had more relapses and a more severe disease with a higher overall and attributable mortality [8]. C. difficile Type 027 was significantly more often acquired at a health care institution. Other frequently isolated PCR ribotypes in The Netherlands were types 014, 001 and 078 .

\section{Norway}

In December 2007, the first two cases of CDI due to Type 027 in Norway were reported from a university hospital in Oslo [18]. 
Surveillance and infection control measures did not reveal other Type 027 isolates at this hospital. In February 2008, a third case of $\mathrm{CDI}$ due to Type 027 was detected at a nursing home in Oslo.

Since January 2008, the Department of Infection Prevention in cooperation with the Institute of Microbiology, both at Rikshospitalet University Hospital, Oslo, have performed genotypic characterisation of $C$. difficile. The most frequently found PCR ribotype is Type 014 . Unfortunately, most medical microbiology laboratories in Norway do not cultivate $C$. difficile. As a consequence, the distribution of PCR ribotypes in Norway remains unknown.

\section{Poland}

No systematic CDI surveillance has yet been developed in Poland. Between 2005 and 2007, a surveillance study was performed in four hospitals in the Mazovia region. Of 400 C. difficile isolates, one isolate belonged to Type 027 . As determined by E-tests, the isolate was highly resistant to fluoroquinolones (ciprofloxacin, gatifloxacin and moxifloxacin, $\mathrm{MIC} \geq 32 \mathrm{mg} / \mathrm{l}$ ) and erythromycin ( $\mathrm{MIC} \geq 256 \mathrm{mg} / \mathrm{l})$, but susceptible to clindamycin $(\mathrm{MIC}=6 \mathrm{mg} / \mathrm{l})$, metronidazole $(\mathrm{MIC}=0.38 \mathrm{mg} / \mathrm{l})$ and vancomycin $(\mathrm{MIC}=0.75 \mathrm{mg} / \mathrm{l})$. The most frequent PCR ribotype was Type 017, which accounted for approximately $40 \%$ of the $C$. difficile isolates studied.

\section{Spain}

Spain does not have a national surveillance programme to investigate cases of CDI or an official reference laboratory where hospitals could send $C$. difficile isolates for further characterisation. A surveillance study performed between January and June 2007 at a 1,750-bed, tertiary care hospital in Madrid revealed two cases of severe CDI due to Type 027. The index case was a Spanish patient admitted to the intensive care unit, who was transferred from a hospital in the United Kingdom. The other patient was a laboratory technician working with $C$. difficile isolates, who developed CDI shortly after antibiotic treatment. In this study, a non-specified PCR ribotype containing the genes for toxins $A$ and $B$ but not for the binary toxin, was detected in 103 of 388 typed $C$. difficile isolates (26.5\%, 81 patients)

Since the $C$. difficile Type 027 has the binary toxin genes, testing for the presence of these genes is performed for all $C$. difficile isolates. Binary toxin-positive strains are subsequently ribotyped. In contrast to previous studies performed in this hospital, there was an increase of non-027 C. difficile containing the genes for toxins $A$ and $B$ and the genes for the binary toxin (13\% of the total number of isolates studied). The PCR ribotype pattern of the binary toxin positive isolates probably corresponds to Type 078.

\section{Sweden}

Three sporadic 'historical' moxifloxacin-susceptible isolates of $C$. difficile Type 027 were found among 1,325 isolates collected between 1997 and 2001 in Sweden. In September 2006, the Swedish Institute for Infectious Disease Control (Smittskyddsinstitutet; SMI) alerted microbiologists and clinicians about $C$. difficile Type 027 and laboratories were encouraged to send $C$. difficile isolates to SMI for microbiological characterisation for patients with a severe course of CDI or when an increased CDI incidence was noticed.

Since epidemic Type 027 isolates have uniformly been moxifloxacin-resistant, a systematic screening of $C$. difficile isolates for moxifloxacin resistance was initiated during 2007 in four hospitals in Stockholm. In February 2008, this screening was extended to include all major hospitals in Sweden. Preliminary results indicate only one case of moxifloxacin-resistant Type 027 (found in May 2008), but there is currently no indication of outbreaks due to $C$. difficile Type 027 . The most frequently PCR ribotypes isolated in Sweden are Types 012 and 014.

\section{Switzerland}

In Switzerland, the first outbreak of $C$. difficile Type 027 was observed in a geriatric hospital in Basel in 2006 [19]. The index case was an 82-year old female patient and the outbreak involved 15 other patients between October 2006 and May 2007. It is likely that the index patient acquired $C$. difficile Type 027 during a hospital stay in a foreign country. The median age of the 16 patients was 83.5 years (interquartile range: $79-92$ years). A severe to moderate course of CDI was reported in seven (44\%) of the patients and crude mortality was $19 \%$ (three deaths). All isolates were highly resistant to moxifloxacin (MIC>32 mg/I), erythromycin (MIC>256 $\mathrm{mg} / \mathrm{l}$ ) and clindamycin (MIC>256 mg/l). MLVA typing revealed one cluster of genetically highly related $(S T R D \leq 2)$ clindamycin-resistant Type 027 isolates which differed from the clindamycin-susceptible Type 027 control isolates and also from clindamycin-resistant isolates from Ireland.

\section{United Kingdom (UK)}

In England and Wales, mandatory surveillance of CDI in patients over 65 years has been included in the healthcare-associated infection surveillance system for acute trusts [20]. This mandatory surveillance programme is operated by the Health Protection Agency (HPA) on behalf of the Department of Health. Through its network of regional laboratories in collaboration with the $C$. difficile Ribotyping Network for England (CDRNE) and the Anaerobe Reference Laboratory (ARL) in Cardiff, the HPA further obtains $C$. difficile isolates from symptomatic patients in a structured, but random sampling scheme. In England, 110 out of 145 hospitals (76\%) investigated between April 2007 and February 2008 showed the presence of $C$. difficile Type 027 . Of 2,084 $C$. difficile isolates, $42 \%$ were typed as Type $027,19 \%$ as Type 106 and 10\% as Type 001. In Wales, 10 out of 16 investigated hospitals showed the presence of $C$. difficile Type 027.

In Scotland all diagnostic laboratories have been requested since September 2006 to submit $C$. difficile isolates to a UK reference laboratory in the case of severe CDI or outbreaks. The data are published quarterly [21]. Additionally, isolates from local research projects have also been submitted for ribotyping, which means that some hospitals/regions are over-represented in this collection of isolates. A total of 20 cases of $C$. difficile Type 027 were identified in Scotland in the period from September 2006 to April 2008. Among these were an outbreak with five cases in one hospital in the West of Scotland and an outbreak with three cases in a hospital in the North East of Scotland. In total, Type 027 has been detected in nine acute care hospitals in five different geographical regions of Scotland. One case was reported from a nursing home.

Until recently, C. difficile Type 027 was not a common PCR ribotype in Scotland. With the two recent outbreaks the frequency of 027 has reached $5.7 \%$. Since 2006, the most frequent PCR ribotypes in Scotland have consistently been type 106 (55\% of C. difficile isolates) and type 001 (21\%). Four isolates of the new emerging ribotype 078 have been identified in Scotland as well.

In Northern Ireland, a survey was undertaken between September and December 2006, and 60 samples $(4.0 \%$ of the annual total of $C$. 


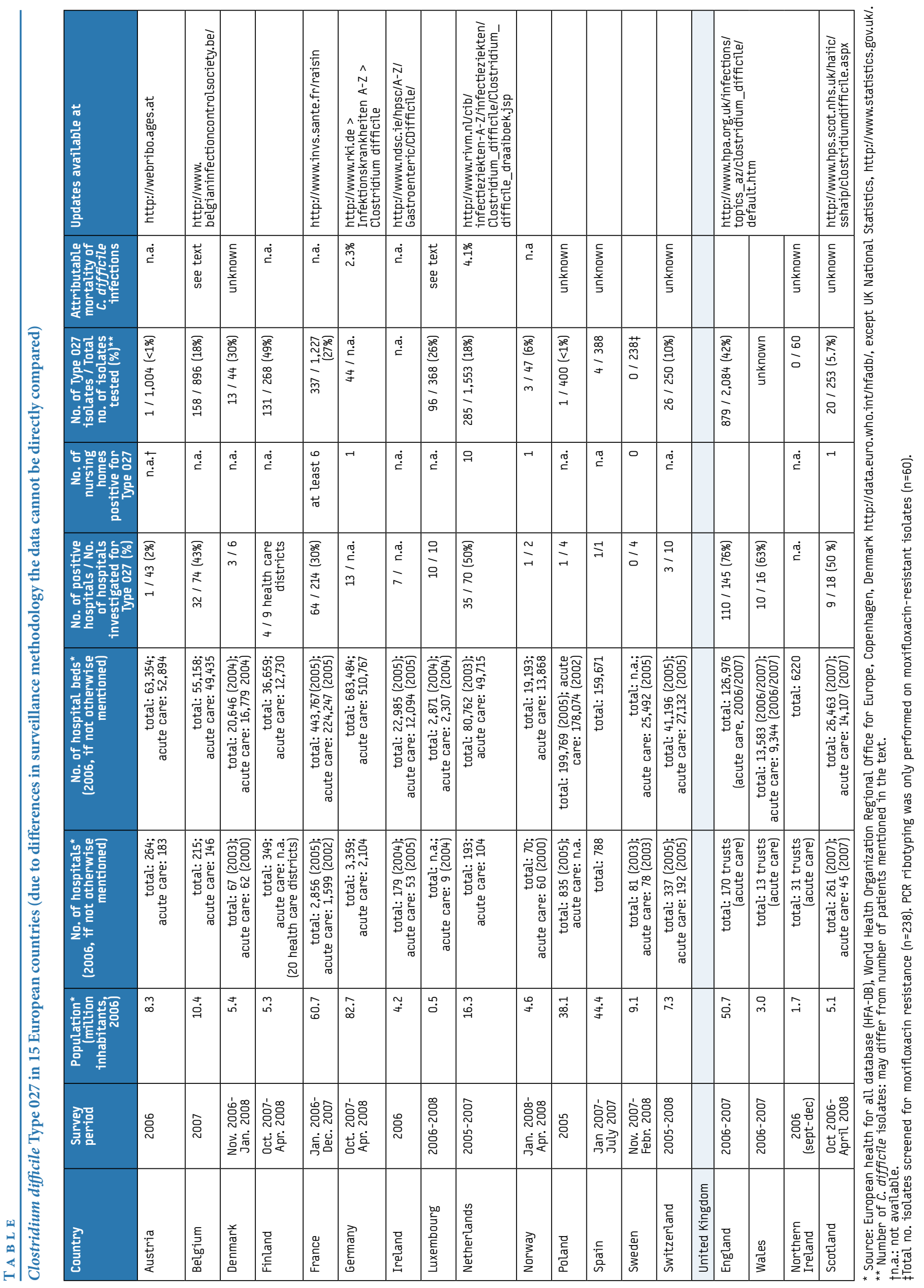


difficile reports) were ribotyped: the most common ribotypes were 001 (35\%), 106 (11.6\%) and 078 (8.3\%). Ribotype 027 was not identified in this small sample. The first report of ribotype 027 in Northern Ireland related to a specimen in mid-June 2007. Since then there has been a large hospital outbreak associated with ribotype 027 (57 reports to date).

An enhanced ribotyping surveillance programme has recently been established: 59 specimens were ribotyped, of which $35 \%$ were Type 078, 25\% were Type 001 and $8 \%$ were Type 014/20. The sample contained two reports of Type 027 (3\%). Compared with the earlier survey in 2006 there has been a marked increase in ribotype 078 and a decrease in ribotype 001 . Further investigations are underway to analyse this change in ribotype incidence.

\section{Conclusion}

As of June 2008, C. difficile Type 027 has been reported from healthcare facilities in 16 European countries (Figure, Table). Among those, nine countries have reported outbreaks and seven countries have reported only sporadic cases. Because of the lack of national surveillance programmes in many countries, it is at present impossible to estimate the incidence of $C$. difficile Type 027 in Europe. A new, emerging Type 078 strain, with similar mechanisms for the hyper-production of toxins as Type 027, is increasingly reported in Belgium, The Netherlands, Northern Ireland, Scotland, and possibly Spain.

\section{F I G U R E}

Distribution of Clostridium difficile Type 027 by country in Europe as of June 2008

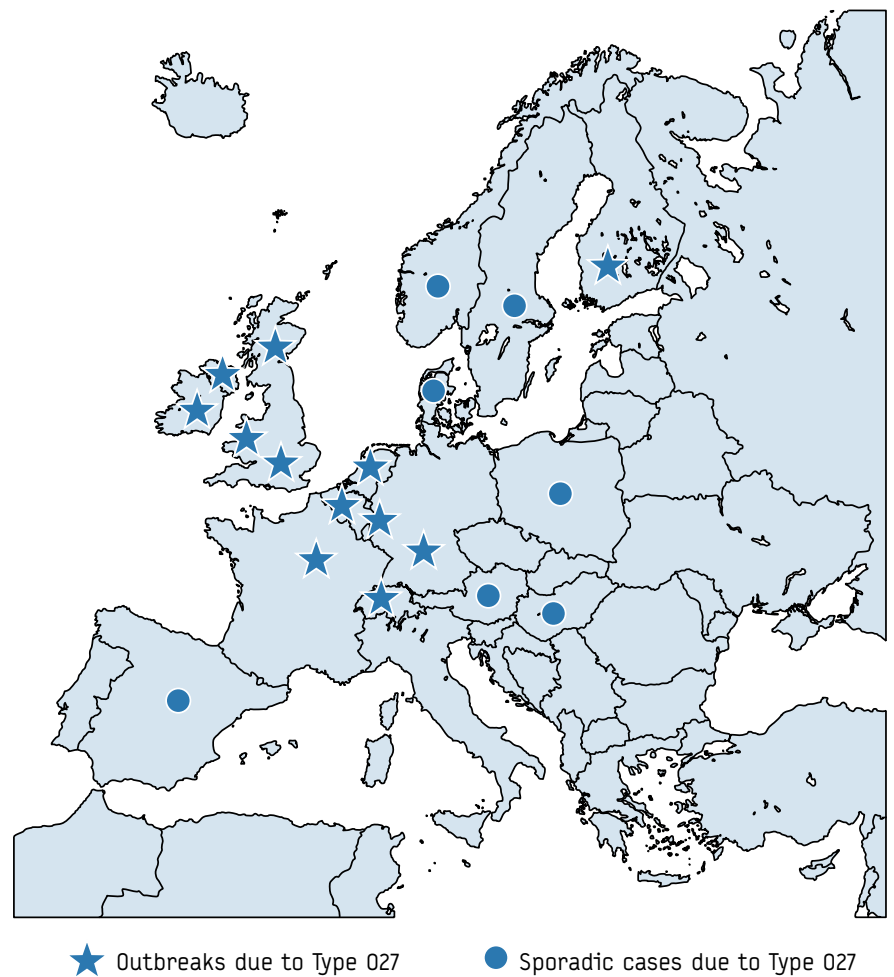

* Not all countries have performed surveillance studies to $C$. difficile type 027 and this figure may underestimate the number of affected countries.
The occurrence of outbreaks due to clindamycin-resistant Type 027 isolates in three European countries is worrying. Clindamycin has been considered as a 'protective' antibiotic with regards to the development of CDI due to Type 027 [8]. However, resistance to clindamycin may increase the risk of CDI in patients receiving this agent and its use may be an important factor contributing to its persistence and spread. In addition, the report of erythromycinsusceptible and clindamycin-susceptible Type 027 isolates in Germany and Denmark indicates that antimicrobial resistance patterns are very dynamic and can no longer be used to identify C. difficile Type 027.

All European countries should now be aware about CDI in healthcare facilities, and specifically about $C$. difficile Type 027 . Surveillance studies should be performed with uniform definitions, as proposed by ECDC [1]. These surveillance studies should not only focus on $C$. difficile Type 027, but include all major PCR ribotypes circulating in Europe since the distribution of these ribotypes varies greatly among European countries and over time.

\section{References}

1. Kuijper EJ, Coignard B, Tull P; the ESCMID Study Group for Clostridium difficile (ESGCD); EU Member States and the European Centre for Disease Prevention and Control (ECDC). Emergence of Clostridium difficile-associated disease in North America and Europe. Clin Microbiol Infect. 2006;12 Suppl 6:2-18.

2. McDonald LC, Killgore GE, Thompson A, Owens RC Jr, Kazakova SV, Sambol SP, et al. An epidemic, toxin gene-variant strain of Clostridium difficile. $N$ Engl J Med. 2005;353(23):2433-41.

3. Loo VG, Poirier L, Miller MA, Oughton M, Libman MD, Michaud S, et al. A predominantly clonal multi-institutional outbreak of Clostridium difficileassociated diarrhea with high morbidity and mortality. N Engl J Med. 2005;353(23):2442-9.

4. Pépin J, Valiquette L, Alary ME, Villemure P, Pelletier A, Forget $\mathrm{K}$, et al. Clostridium difficile-associated diarrhea in a region of Quebec from 1991 to 2003: a changing pattern of disease severity. CMAJ. 2004;171(5):466-72.

5. Barbut F, Mastrantonio P, Delmée M, Brazier J, Kuijper E, Poxton I, et al. Prospective study of Clostridium difficile-associated disease in Europe with phenotypic and genotypic characterization of the isolates. Clin Microbiol Infect. 2007;13(11):1048-57.

6. Kuijper EJ, van Dissel JT, Wilcox MH. Clostridium difficile: changing epidemiology and new treatment options. Curr Opin Infect Dis. 2007;20(4):376-83.

7. Paltansing S, van den Berg RJ, Guseinova RA, Visser CE, van der Vorm ER, Kuijper EJ. Characteristics and incidence of Clostridium difficile-associated disease in The Netherlands, 2005. Clin Microbiol Infect. 2007;13(11):1058-64.

8. Goorhuis A, Van der Kooi T, Vaessen N, Dekker FW, Van den Berg R, Harmanus C, et al. Spread and epidemiology of Clostridium difficile polymerase chain reaction ribotype 027/toxinotype III in The Netherlands. Clin Infect Dis. 2007:45(6):695-703.

9. Kuijper EJ, Coignard B, Brazier JS, Suetens C, Drudy D, Wiuff C, et al. Update of Clostridium difficile-associated disease due to PCR ribotype 027 in Europe. Euro Surveill. 2007;12(6):pii=714. Available from: http://www.eurosurveillance. org/ViewArticle.aspx?ArticleId $=714$

10. Centers for Disease Control and Prevention (CDC). Surveillance for communityassociated Clostridium difficile--Connecticut, 2006. MMWR Morb Mortal Wkly Rep 2008;57(13):340-3.

11. Indra A, Huhulescu S, Hasenberger P, Schmid D, Alfery C, Wuerzner R, et al. First isolation of Clostridium difficile PCR ribotype 027 in Austria. Euro Surveill. 2006;11(37):pii=3046. Available from: http://www.eurosurveillance. org/ViewArticle.aspx?ArticleId=3046

12. Lyytikäinen O, Mentula S, Kononen E, Kotila S, Tarkka E, Anttila VJ. First isolation of Clostridium difficile PCR ribotype 027 in Finland. Euro Surveill. 2007;12(45):pii=3303. Available from: http://www.eurosurveillance.org/ ViewArticle.aspx?ArticleId=3303

13. Kleinkauf N, Weiss B, Jansen A, Eckmanns T, Bornhofen B, Kuehnen E, et al. Confirmed cases and report of clusters of severe infections due to Clostridium difficile PCR ribotype 027 in Germany. Euro Surveill. 2007:12(46):pii=3307. Available from: http://www.eurosurveillance.org/ ViewArticle aspx?ArticleId $=3307$ 
14. Zaiss NH, Weile J, Ackermann G, Kuijper EJ, Witte W, Nuebel U. A case of Clostridium difficile-associated disease due to the highly virulent clone of Clostridium difficile PCR ribotype 027, March 2007 in Germany. Euro Surveill. 2007;12(46):pii=3306. Available from: http://www.eurosurveillance. org/ViewArticle. aspx?ArticleId=3306

15. Long S, Fenelon L, Fitzgerald S, Nolan N, Burns K, Hannan M, et al. First isolation and report of clusters of Clostridium difficile PCR 027 cases in Ireland. Euro Surveill. 2007;12(17):pii=3183. Available from: http://www. eurosurveillance.org/ViewArticle.aspx?ArticleId=3183

16. Drudy D, Goorhuis A, Bakker D, Kyne L, van den Berg R, Fanning S, et al. Clindamycin-resistant clone of Clostridium difficile PCR ribotype 027, Europe. Emerg Infect Dis. In press 2008.

17. Clostridium difficile Sub-Committee. Surveillance, Diagnosis and Management of Clostridium difficile - associated disease in Ireland. Dublin: Health Protection Surveillance Centre; 2008. ISBN 978-0-9551236-3-4. Available from: http://www.ndsc.ie/hpsc/A-Z/Gastroenteric/Clostridiumdifficile/Publications/ File,2936,en.pdf

18. Ingebretsen A, Hansen G, Harmanus C, Kuijper EJ. First confirmed cases of Clostridium difficile PCR ribotype 027 in Norway. Euro Surveill. 2008;13(2):pii=8011. Available from: http://www.eurosurveillance.org/ ViewArticle.aspx?ArticleId $=8011$

19. Fenner L, Widmer AF, Stranden A, Conzelmann M, Goorhuis A, Harmanus C, et al. First cluster of clindamycin-resistant Clostridium difficile PCR-ribotype 027 associated disease in Switzerland. Clin Microbiol Infect. 2008;14(5):514-5.

20. Brazier JS, Patel B, Pearson A. Distribution of Clostridium difficile PCR ribotype 027 in British hospitals. Euro Surveill. 2007;12(17):pij=3182. Available from: http://www.eurosurveillance.org/ViewArticle. aspx?ArticleId=3182

21. The Health Protection Scotland (HPS) C. difficile Working Group. Quarterly report on the Surveillance of Clostridium difficile Associated Disease (CDAD) in Scotland, January 2008 - March 2008. HPS Weekly Report. 2008;42(27).

This article was published on 31 July 2008.

Citation style for this article: Kuijper EJ, Barbut F, Brazier JS, Kleinkauf N, Eckmanns T, Lambert ML, Drudy D, Fitzpatrick F, Wiuff C, Brown DJ, Coia JE, Pituch H, Reicher $P$, Even J, Mossong J, Widmer AF, Olsen KE, Allerberger F, Notermans DW, Delmée M, Coignard B, Wilcox M, Patel B, Frei R, Nagy E, Bouza E, Marin M, Akerlund T, VirolainenJulkunen A, Lyytikäinen 0, Kotila S, Ingebretsen A, Smyth B, Rooney P, Poxton IR, Monnet DL. Update of Clostridium difficile infection due to PCR ribotype 027 in Europe, 2008. Euro Surveill. 2008;13(31):pii=18942. Available online: http://www.eurosurveillance. org/ViewArticle.aspx?ArticleId=18942 